\title{
Type II (adult onset) citrullinaemia: clinical pictures and the therapeutic effect of liver transplantation
}

\author{
S Ikeda, M Yazaki, Y Takei, T Ikegami, Y Hashikura, S Kawasaki, M Iwai, K Kobayashi, \\ T Saheki
}

Third Department of Medicine, Shinshu University School of Medicine, Matsumoto 390-8621, Japan S Ikeda

M Yazaki

Y Takei

First Department of Surgery, Shinshu University School of Medicine, Matsumoto 390-8621, Japan

T Ikegami

Y Hashikura

S Kawasaki

First Department of Internal Medicine, Iwate Medical

University, Morioka 020-8505, Japan M Iwai

Department of Biochemistry, Faculty of Medicine, Kagoshima University, Kagoshima 890-8520, Japan

K Kobayashi

T Saheki

Correspondence to:

Dr S Ikeda

ikedasi@

hsp.md.shinshu-u.ac.jp

Received 19 April 2001 and in revised form

26 June 2001

Accepted 6 July 2001

\begin{abstract}
Objective-Adult onset type II citrullinemia is an inherited disorder of amino acid metabolism caused by a deficiency of liver specific argininosuccinate synthetase activity. Most of the patients with this disease were reported in Japan and therefore, this disease has not been well recognised outside this country. The detailed clinical pictures of the patients with type II citrullinaemia are reported and their outcomes after liver transplantation referred to.

Methods-Ten patients with this disease were evaluated. Seven of them underwent liver transplants using a graft obtained from a healthy family member.

Results-There were six men and four women; the age of onset of encephalopathy ranged from 17 to 51 years. The initial symptom in nine patients was sudden onset disturbance of consciousness, and one patient had long been regarded as having a chronic progressive psychotic illness. High concentrations of plasma citrulline and ammonia were commonly seen on admission. Although brain CT or MRI lacked any consistent findings, the EEG was abnormal in all patients, showing diffuse slow waves. Additionally, in five patients chronic pancreatitis preceded the onset of encephalopathy. After liver transplantation the metabolic abnormalities, including abnormal plasma concentrations of citrulline and ammonia, were immediately corrected and all neuropsychic symptoms soon disappeared, except for impaired cognitive function in one patient. Six out of these seven patients returned to their previous social lives, including work.

Conclusions-The clinical concept of adult onset type II citrullinaemia coincides well with the range of hepatic encephalopathy, and liver transplantation is a very promising therapeutic approach. (F Neurol Neurosurg Psychiatry 2001;71:663-670)
\end{abstract}

Keywords: citrullinaemia; urea cycle disorder;hepatic encephalopathy; liver transplantation

Citrullinaemia is a rare hereditary metabolic disorder characterised by highly increased concentrations of citrulline and ammonia in the plasma, which is ascribed to a deficiency of argininosuccinate synthetase (ASS), one of the five urea cycle enzymes mainly located in the liver. ${ }^{1}$ This disorder can be classified into three types $^{2}$ : neonatal/infantile (types I and III) and adult (type II). Classic types I and III citrullinaemia (the neonatal/infantile forms: CTLN1) are known to be caused by mutations of the ASS gene, ${ }^{34}$ whereas in patients with type II citrullinaemia (CTLN2) no primary defect has been found within the ASS gene locus. ${ }^{5}$ Recently, however, the causative gene of type II citrullinaemia was identified as the "citrin gene" (SLC25A13). ${ }^{67}$ Patients with type II citrullinaemia display various neurological manifestations closely resembling those of hepatic encephalopathy. In the past, most patients usually followed rapidly deteriorating clinical courses and died of severe brain oedema within a few years of onset, ${ }^{8}$ but some patients with this disease have recently been treated with liver transplantation..$^{8-12}$

In this report we describe the clinical pictures of 10 patients with the disease, including the therapeutic effects of liver transplantation.

\section{Patients and methods}

From 1990 to 2000, 10 patients (six men and four women) with type II citrullinaemia were examined. They were diagnosed according to criteria described previously ${ }^{213}$ : high concentrations of plasma citrulline and ammonia, a slight increase in plasma concentration of arginine, and a marked decrease in hepatic ASS activity with normal kinetic properties (table 1). All the patients were shown to be homozygous or compound heterozygous for mutations of the citrin gene, as already reported elsewhere. ${ }^{67}$ On admission the EEG, CT, and MRI examinations were routinely performed and additionally, six patients who were available had brain single photon emission computed tomography (SPECT) using ${ }^{123}$ I-IMP.

Seven of the 10 underwent liver transplantation. In Japan, full liver transplantation from cadaveric donors is uncommon because brain death is not yet widely recognised as a definition of death, and as an alternative we performed liver transplantation using grafts from living donors, consisting of patients' fathers, mothers, or siblings, all of whom were shown to have normal plasma concentrations of citrulline and ammonia and also to have well preserved urea cycle enzymatic activity in biopsied liver tissue. The details of the operative technique have been reported elsewhere. ${ }^{1415}$ Briefly, during the operation, the 
Table 1 Clinical summary and laboratory data

\begin{tabular}{|c|c|c|c|c|c|c|c|c|c|c|c|c|c|}
\hline \multirow[b]{2}{*}{ Patient } & \multirow[b]{2}{*}{$\begin{array}{l}\text { Age at } \\
\text { onset }\end{array}$} & \multirow[b]{2}{*}{$\operatorname{Sex}$} & \multirow{2}{*}{$\begin{array}{l}\text { Duration of } \\
\text { illness } \\
\text { preop/postop } \\
\text { (months) }\end{array}$} & \multirow[b]{2}{*}{$C T / M R I$} & \multirow[b]{2}{*}{ SPECT } & \multirow{2}{*}{$\begin{array}{l}\text { ASS activity } \\
\text { in liver } \\
\text { (U/mg } \\
\text { protein) }\end{array}$} & \multicolumn{3}{|c|}{ Plasma (on admission) } & \multirow{2}{*}{$\begin{array}{l}\text { Serum } \\
\text { PSTI } \\
(\mathrm{ng} / \mathrm{ml})\end{array}$} & \multicolumn{3}{|c|}{$\left({ }^{*}\right.$ After transplantation) } \\
\hline & & & & & & & $\begin{array}{l}\text { Citrulline } \\
\text { (nmol/ml) }\end{array}$ & $\begin{array}{l}\text { Ammonia } \\
(\mu g / d l)\end{array}$ & $\begin{array}{l}\text { Arginine } \\
(\mathrm{nmol} / \mathrm{ml})\end{array}$ & & $\begin{array}{l}\text { Citrulline } \\
\text { (nmol/ml) }\end{array}$ & $\begin{array}{l}\text { Ammonia } \\
(\mu g / d l)\end{array}$ & $\begin{array}{l}\text { Arginine } \\
(\mathrm{nmol} / \mathrm{ml})\end{array}$ \\
\hline 1 & 24 & Male & 7 & $\mathrm{~N}$ & - & 0.0039 & 571.0 & 317 & 297.9 & - & - & - & - \\
\hline 2 & 25 & Male & 43 & $\mathrm{~N}$ & $\mathrm{~N}$ & 0.0030 & 794.6 & 137 & 119.7 & 14.0 & - & - & - \\
\hline 3 & 12 & Female & $118 / 29$ & A & A & 0.0068 & 174.9 & 685 & 128.3 & 120.0 & 37.4 & 64 & 113.4 \\
\hline 4 & 51 & Female & $8 / 6$ & A & A & 0.00032 & 668.5 & 520 & 242.2 & 21.0 & 28.6 & 34 & 60.9 \\
\hline 5 & 29 & Male & 21 & $\mathrm{~N}$ & A & 0.00167 & 1500.6 & 118 & 1589.0 & 13.0 & - & - & - \\
\hline 6 & 24 & Male & $7 / 65$ & $\mathrm{~N}$ & - & 0.0018 & 782.2 & 165 & 279.1 & 123.2 & 55.1 & 50.0 & 124.6 \\
\hline 7 & 44 & Male & $11 / 50$ & $\mathrm{~N}$ & - & 0.0044 & 167.4 & 172 & 154.4 & 260.0 & 36.8 & 34.0 & 102.9 \\
\hline 8 & 23 & Female & $7 / 32$ & $\mathrm{~N}$ & - & 0.0012 & 207.5 & 213 & 111.5 & - & 28.5 & 30 & 144.0 \\
\hline 9 & 17 & Female & $5 / 26$ & A & A & 0.0013 & 498.1 & 201 & 199.6 & 29.0 & 34.6 & 103 & 70.8 \\
\hline 10 & 20 & Male & $144 / 13$ & A & A & 0.00103 & 404.2 & 91 & 166.9 & 35.0 & 54.0 & 74 & 105.9 \\
\hline
\end{tabular}

$\mathrm{N}=$ Normal; $\mathrm{A}=$ abnormal; $-=$ not examined.

The following urea cycle enzyme activities were assayed using the biopsied liver tissue: carbamylphosphate synthetase, ornithine transcarbamylase, argininosuccinate synthetase (ASS), argininosuccinate lyase, arginase, and except ASS all other enzyme activities were normal in these 10 patients.

Normal values: ASS $0.033 \pm 0.012 \mathrm{U} / \mathrm{mg}$ protein, citrulline: $10.8-36.5 \mathrm{nmol} / \mathrm{ml}$, ammonia: $<41 \mu \mathrm{g} / \mathrm{dl}$, arginine: $39.6-138.4 \mathrm{nmol} / \mathrm{ml}$, PSTI: $4.6-12.2 \mathrm{ng} / \mathrm{ml}$.

patient's whole liver was removed. The left lobe was harvested from the living donor and transplanted orthotopically.

The postoperative follow up for the patients ranged from 6 to 65 months. During this period, neurological examination, routine laboratory tests including measurement of plasma concentrations of amino acids and ammonia, EEG, and brain MRI were regularly carried out. Brain SPECT was also performed on five of these seven patients.

\section{Results}

CASE REPORTS

Patient 1

The patient was a 25 year old businessman. $\mathrm{He}$ suddenly went into a delirious state in February 1990 and was admitted to hospital; he showed violent flapping tremor and very high concentrations of plasma ammonia $(317 \mu \mathrm{g} / \mathrm{dl})$ and citrulline $(571.0 \mathrm{nmol} / \mathrm{ml})$. Intravenous infusion of arginine and branched amino acids was started, and he wasgiven a low protein diet (protein content $40 \mathrm{~g} /$ day). However, in the subsequent 5 months a delirious state with abnormal behaviour recurred five times. At the end of July he was transferred to our hospital.

$\mathrm{He}$ was $182 \mathrm{~cm}$ tall and weighed $54 \mathrm{~kg}$. He was alert, and neurological examinations were normal. Although routine laboratory data (including electrolytes, liver, and renal function tests) were unremarkable, the plasma concentrations of ammonia and citrulline were still high. He was scheduled to receive preoperative examinations, but during the next 2 weeks disorientation and emotional lability repeatedly appeared despite intensive therapy with intravenous infusion of arginine and branched amino acids, and oral administration of lactulose $(60 \mathrm{ml} /$ day). The plasma concentration of ammonia gradually increased, finally reaching $820 \mu \mathrm{g} / \mathrm{dl}$, and the patient fell into a deep coma. Plasma exchange and peritoneal dialyses were repeated several times, but the encephalopathy did not improve (fig 1). At the end of September he died. The duration of illness was 7 months.

\section{Patient 2}

The patient was a 25 year old cook. He had been abnormally fond of peanuts since childhood. He had a history of chronic pancreatitis and at the age of 16 underwent pancreaticojejunostomy to relieve this disorder. One night in April 1997 he suddenly woke up, shrieked, and started banging his head violently against the wall. The next morning he was normal. He experienced a similar attack one month later: he suddenly attacked his friends without any reason and at that time looked extremely excited. He was taken to a local hospital where highly increased plasma concentrations of ammonia $(137 \mu \mathrm{g} / \mathrm{dl})$ and citrulline (794.6 $\mathrm{nmol} / \mathrm{ml}$ ) were detected.

At examination, he was $162 \mathrm{~cm}$ tall and weighed $53 \mathrm{~kg}$. He was alert and neurological findings were normal. Intravenous infusion of arginine and branched amino acids was started, with restriction of oral protein intake (40 g/day), and oral administration of lactulose (90 ml/day) and kanamycin (1.5 g/day) was added. Plasma concentrations of ammonia and citrulline decreased but remained abnormally high. During his stay in hospital he sometimes fell into a delirious state, accompanied by a flapping tremor, but these episodes were usually relieved within 2 or 3 days by stopping oral intake of food. He did not want to undergo liver transplantation. Since discharge he has been receiving intravenous infusions of arginine and branched amino acids every day at the outpatient department and taking the same medicines. In the past 3 years he has had six attacks of disturbed consciousness, all of which have led to admission to hospital for a few days, and he remains unemployed.

\section{Patient 3}

This patient was 21 years old when she visited us. She had been very fond of soybean products since childhood. After entering junior high school she often complained of severe headache, appetite loss, and insomnia. She was first diagnosed as having depression at the age of 15 , but auditory and visual hallucinations and catatonic behaviour appeared and diagnosis was changed to schizophrenia. From the age of 18 she often experienced syncopal attacks and also showed abnormal behaviour including destroying utensils and injuring herself. The alternating appearance of severe anorexia and excessive eating further worsened her condition. In January 1998 (at the age of 21) she was admitted to another hospital because of 
prolonged loss of consciousness. High concentrations of plasma ammonia $(685 \mu \mathrm{g} / \mathrm{dl})$ and citrulline $(174.9 \mathrm{nmol} / \mathrm{ml})$ were detected.

At examination she was $171 \mathrm{~cm}$ tall, weighed $46 \mathrm{~kg}$, and laboratory data showed a moderately increased serum concentration of triglyceride $(374 \mathrm{mg} / \mathrm{dl}$, normal: $<150 \mathrm{mg} / \mathrm{dl})$. She received a liver transplant using a graft obtained from her father, aged 50. After operation her neuropsychological condition changed dramatically: her severely depressive and catatonic mood disappeared and she became very cooperative, with frequent smiling. Syncope did not recur and her mental ability rapidly improved (her score on the Japanese Wechsler adult intelligence scale-revised was 40 on admission and 79 at 3 months after the operation (normal around 80)). Since discharge she has been helping her mother with housework.

Patient 4

The patient was a 52 year old woman on referral. In August 1999, she noticed severe general fatigue and transient dysarthria; a few days later she was found in a comatose state with generalised tonic-clonic convulsion at her home and was admitted to a local hospital. Her disturbed consciousness continued for several days, and then improved. Because a high concentration of plasma ammonia $(520 \mu \mathrm{g} /$ day $)$ was detected sodium benzoate ( $7.5 \mathrm{~g}$ /day) was given. After discharge the plasma concentration of ammonia remained high (300-400 $\mu \mathrm{g} / \mathrm{dl})$ and her mental state gradually deteriorated with intermittent appearance of violent hand tremor. In January 2000 she was readmitted to hospital because of a severe apathetic state and MRI showed an extensive cerebral white matter lesion (fig 2). She was switched to hyperalimentation with branched amino acids and her conscousness improved.

At examination in April 2000, she was 152.5 $\mathrm{cm}$ tall and weighed $48 \mathrm{~kg}$. Neurological examination showed normal somatic motor and sensory functions, but cognitive functions were seriously distrubed: she had recent memory loss and transcortical sensory aphasia, the second being predominant. Evaluation using the Japanese Wechsler adult intelligence scalerevised was impossible, and instead she was given the mini mental state examination, achieving a score of 11/30. In May she received a liver transplant using a graft obtained from her younger brother, aged 46. After the operation her cognitive function remained unchanged, but she has been managing without much help since discharge.

\section{CLINICAL SUMMARY OF THE REMAINING SIX} PATIENTS

\section{Patient 5}

This 30 year old male patient experienced the first episode of temporarily altered consciousness and abnormal behaviour in July 1993 and then he had repeated transient bouts of deep coma during the next 6 months despite intensive medications. He went abroad to receive a conventional liver transplant from a cadaveric donor in March 1994. While he was waiting for surgery severe encephalopathy recurred, and he died in April. The duration of illness was 21 months.

Low protein diet

$$
40 \mathrm{~g} / \mathrm{day}
$$

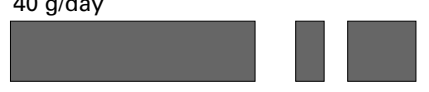

Fluid containing branched amino acids

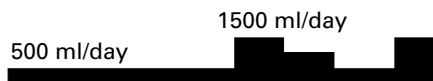

$1000 \mathrm{ml} /$ day

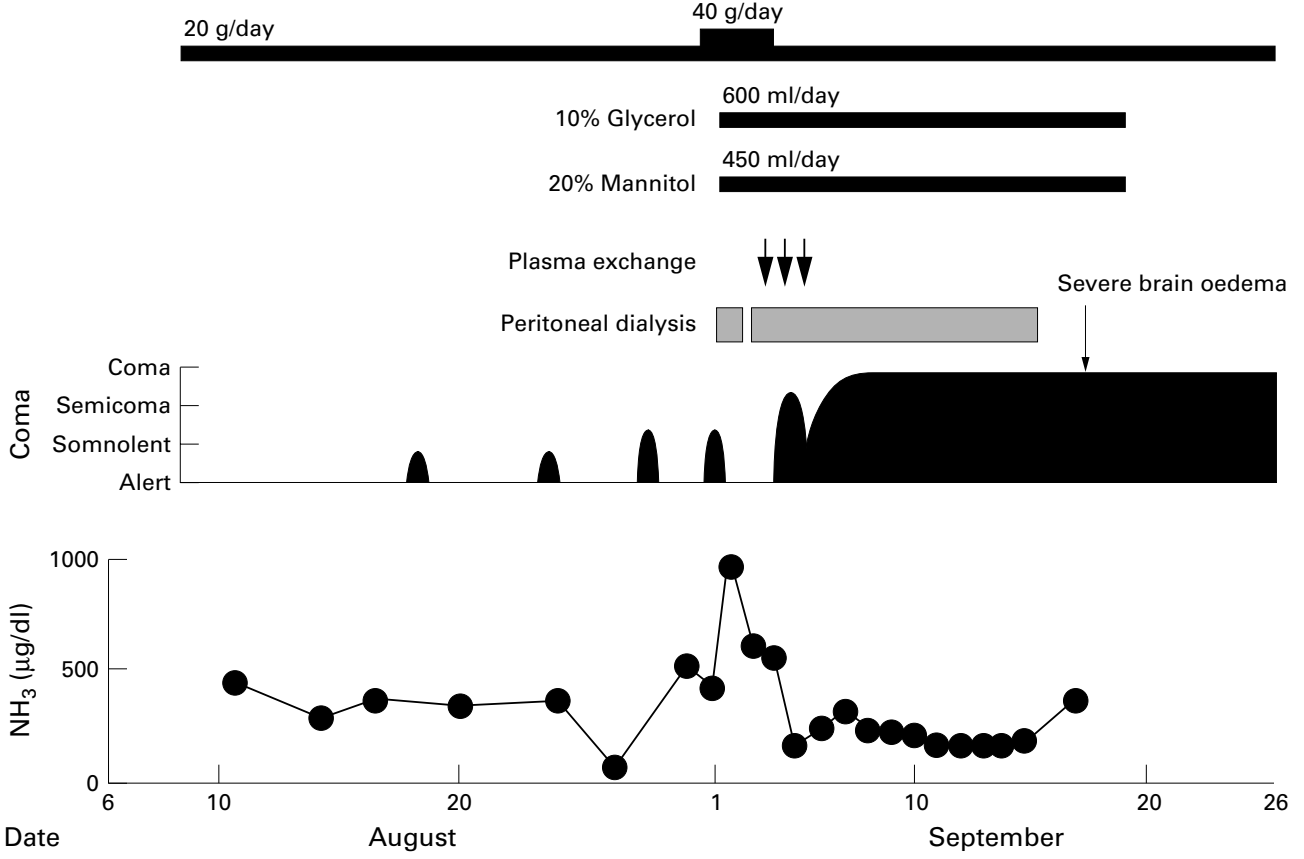

Figure 1 Clinical course of patient 1. 
Patient 6

The patient was a 25 year old man with a 6 month history of this disease, showing recurrent attacks of unconsciousness. His parents were second cousins. He had a somewhat increased serum concentration of triglyceride (303 mg/dl). In June 1995 he had a liver transplant using a graft obtained from his 61 year old father. He started to work as a businessman again 10 months after the operation. During the postoperative 5 years he has not experienced any serious psychophysical problems. This was the first patient with citrullinaemia to be successfully treated by liver transplantation from a live donor. ${ }^{10}$

Patient 7

At the age of 43 this patient was admitted to another hospital because of severe epigastric pain. A raised serum concentration of amylase was found $(652 \mathrm{IU} / 1$, normal <120 IU/1) and he was diagnosed as having relapsing chronic pancreatitis. At the same time he was found to have a highly increased concentration of serum triglyceride $(751 \mathrm{mg} / \mathrm{dl})$. In October 1995, when he was 44 , he had his first attack of delirium. In September 1996 the patient, aged 45, underwent liver transplantation using a graft obtained from his 20 year old son. He started to work again 6 months after the operation, and none of his neurological symptoms have recurred during the postoperative 4 years.

\section{Patient 8}

This female patient had had chronic pancreatitis since her teens and underwent pancreaticojejunostomy at the age of 17. In August 1997, aged 23 , she suddenly became comatose. Gait disturbance, difficulty in reading, and abrupt episodes of nausea and vomiting then appeared. She had a highly increased concentration of serum triglyceride $(918 \mathrm{mg} / \mathrm{dl})$. In March 1998, the patient, aged 24, underwent liver transplantation using a graft obtained from her 54 year old father Since discharge she has been working in an office.

\section{Patient 9}

This female patient had been very fond of soybean products since childhood. At the age of 4 she had generalised tonic-clonic convulsions and had been treated with several types of antiepileptic drugs, but still experienced occasional seizures. In April 1998 (at the age of 17) she developed attacks of unconscousness with the intermittent appearance of violent hand tremor. Then her seizures became more severe even though she was taking medication. Liver transplantation was performed in September 1998. The donor was her father, aged 48. After

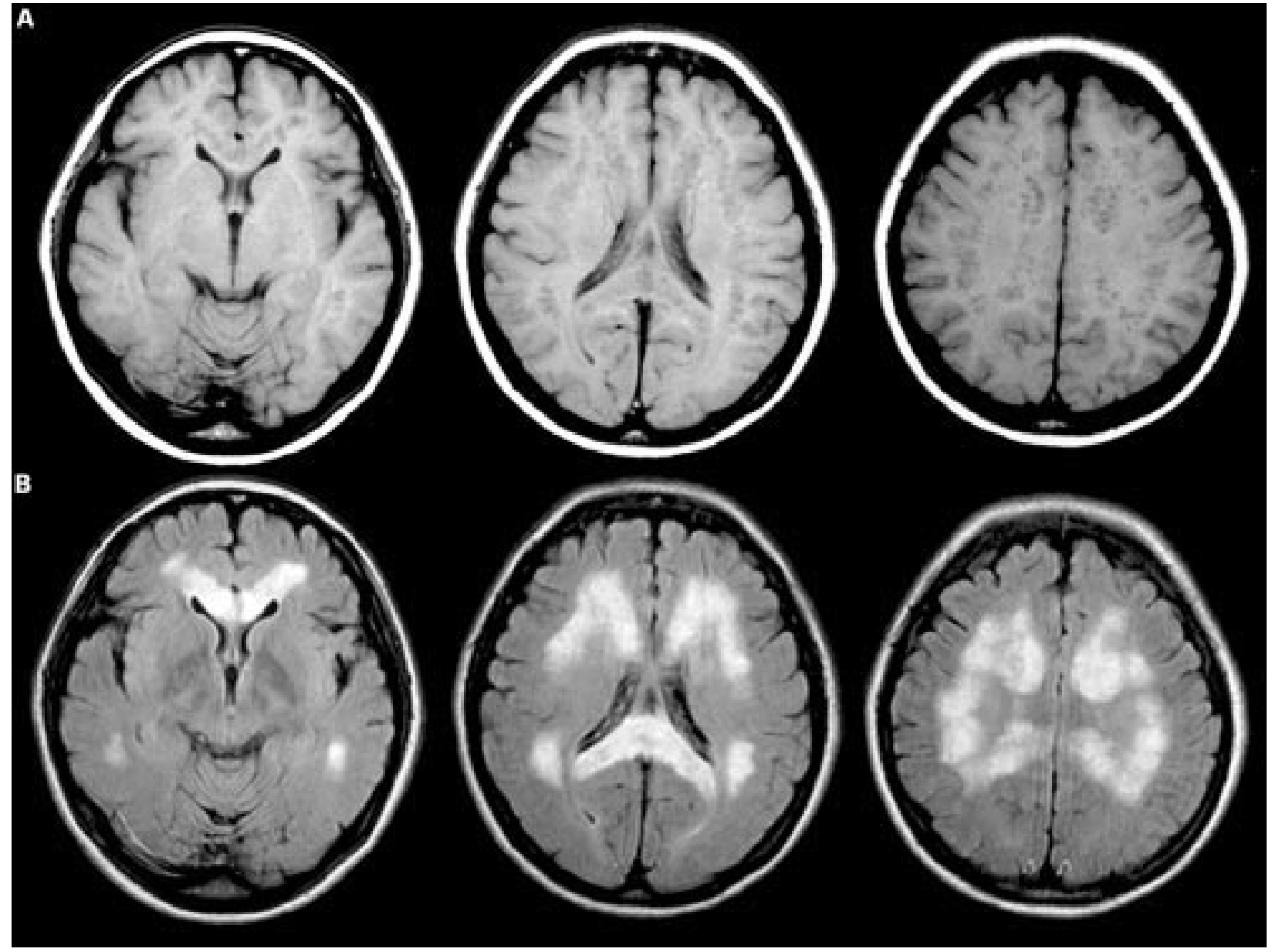

Figure 2 Brain MRI findings in patient 4. Spotty necrotic lesions with oedema are present in an extensive area of subcortical white matter and corpus callosum. (A)T1 weighted image; (B)T2 weighted image. 
the operation, her mental activity improved and epilepsy has been well controlled by 1800 $\mathrm{mg} /$ day valproric acid.

\section{Patient 10}

This male patient was 32 years old. When he was 18 years old he was admitted to hospital because of acute pancreatitis. At the age of 19 he underwent a pancreaticojejunostomy but he still had occasional attacks of severe epigastralgia. At the age of 20 he was first affected by loss of consciousness and was started on therapy including a low protein diet ( $40 \mathrm{~g} /$ day). After the age of 30 episodes of unconsciousness recurred often, usually accompanied by the prodromal symptoms of blurred vision and dysarthria. Finally he fell into a prolonged coma with violent flapping tremor in May 1999. In September 1999, he received a liver transplant using a graft from his 57 year old mother. He has been working after discharge.

\section{EEG FINDINGS}

Findings varied according to the state of consciousness of the patients: when they were alert EEG findings were normal, but when they were confused, the EEG showed diffuse slow waves including frequent discharges of triphasic waves. In addition to the appearance of these diffuse slow waves, occasional discharges of spike and wave complexes were seen in patients 3 and 9. After liver transplantation
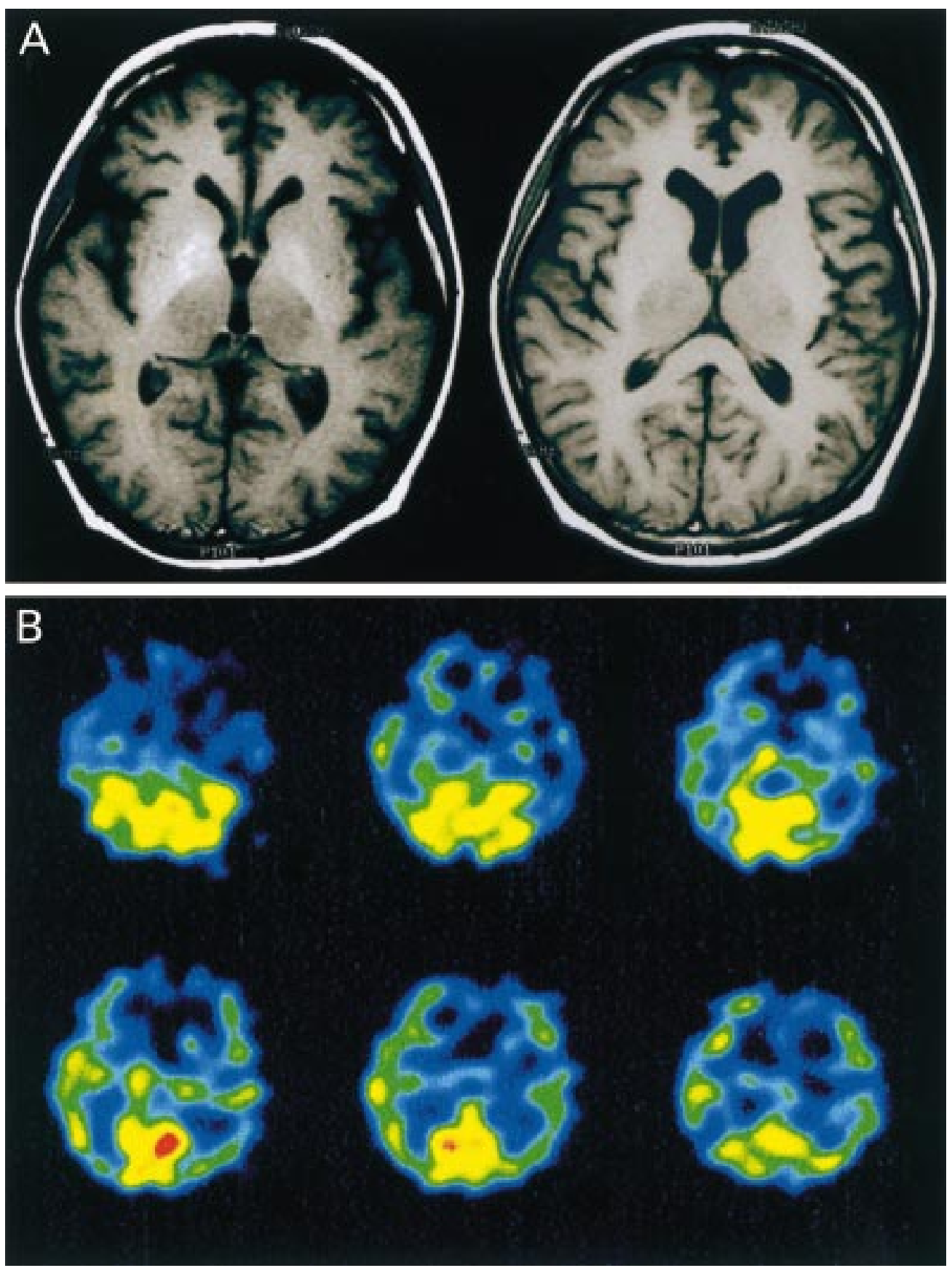

Figure 3 Brain MRI and SPECT findings in patient 3. (A) MRI on admission. Cortical atrophy in the frontotemporal lobe is apparent. (T1 weighted image). (B) Early images of ${ }^{123}$ I-IMP SPECT in patient 3 taken 3 years postoperatively. Decreased uptake of isotope is still seen in an extensive area of the cerebrum, especially in the frontotemporal lobes. 
these abnormal EEG findings disappeared within 3 months in five patients. In patient 9 the frequency of spike and wave complexes has been decreasing. In patient 4 triphasic waves were not seen but diffuse slow waves still remained 5 months postoperatively.

\section{CT AND MRI IMAGES}

On admission abnormal findings were seen in patients 3,4,9, and 10 . The findings in patient 4 were mentioned above. In patients 3 and 10 slight atrophy of the frontotemporal cortices was noted (fig $3 \mathrm{~A}$ ). In patient 9 diffuse cortical atrophy was seen, especially in the right parieto-occipital area. During follow up periods all findings in these four patients were unchanged.

\section{${ }^{123}$ I-IMP SPECT IMAGES}

brain SPECT images were examined in patients $2,3,4,5,9$, and 10 . The scan was performed within 20 minutes of radiotracer injection. On admission patient 2 had a normal appearance, but the pattern had changed 3 years later, with a significant decrease in radionuclide uptake, especially in the cerebral cortices. Patient 5 showed a slight decrease in radionuclide uptake in an extensive area of the cerebral cortices and basal ganglia. In patients $3,4,9$, and 10 the SPECT images were evaluated before and after liver transplantation: in the preoperative examination they disclosed a marked decrease in radionuclide uptake in an extensive area of brain, but in postoperative examinations no significant changes in radionuclide uptake were seen during 6 to 36 month follow up (fig 3 B).

LIVER FINDINGS

Abdominal CT was carried out on all patients at admission. Patients 2, 5, 7, and 8 showed a normal liver but the remaining six patients (patients 1, 3, 4, 6, 9, and 10) showed diffuse low density, indicating a fatty liver. No splenomegaly was seen. At gross examination at operation, the livers in all seven patients showed moderate to marked enlargement and looked yellowish and waxy. Histology commonly showed moderate to severe fatty metamorphosis.

\section{Discussion}

CLINICOPATHOLOGICAL FEATURES

Adult onset type II citrullinaemia (CTLN2) is now known to be one form of deficiency in urea cycle enzymes ${ }^{2}$ and is caused by mutations of the citrin gene, ${ }^{16}$ but the original description of this disorder possibly dates back to the Japanese literature in the 1960s: Shiraki et al ${ }^{17}$ and $\mathrm{Oda}^{18}$ reported an unusual form of encephalopathy as a pseudoulegyria type of hepatocerebral disease. Their clinicopathological study involved eight men and three women whose ages ranged from 20 to 31 . They commonly showed a sudden onset of consciousness disturbance, such as disorientation, restlessness, abnormal behaviour, and drowsiness, and at the same time a remarkable flapping tremor. Similar attacks repeatedly appeared, and patients experienced convulsions, impaired cognitive functions, and limb paralysis in the more advanced stage. From 4 months to 2 years after onset, all patients were in "das appallische Syndrom"described by Kretschmer $^{19}$ and also showed severe general emaciation. In four of them a raised concentration of plasma ammonia was detected and six patients had a history of a unbalanced diet, especially eating large amounts of peanuts or soybean products including tofu, a curd made from soybeans. At necropsy all brains showed marked gross atrophy, mainly in the temporoparietal lobes. The characteristic histology was extensive and severe loss of cortical neurons without reactive gliosis, which was, therefore, called the pseudoulegyria type. ${ }^{17}{ }^{18}$ No abnormal vessels indicating the presence of portal-systemic shunt were found in the liver. Liver histology was described in six patients ${ }^{20}$ : two showed steatosis and the remaining four had severe fatty metamorphosis with slight to moderate fibrotic changes. In the late 1970s to early 1980s patients presenting with a clinical picture of the pseudoulegyria type of hepatocerebral disease were consistently shown to have very high concentrations of plasma citrulline in addition to hyperammonaemia, ${ }^{21}$ and a deficiency of ASS activity in the liver was found to be responsible for this disorder. ${ }^{22} 23$

Our 10 patients well satisfied the diagnostic criteria of type II citrullinaemia. The sex ratio was $6: 4$, being male dominant, and the age of onset of encephalopathy ranged from 17 to 51 years. On the basis of gene analysis the pattern of inheritance is autosomal recessive ${ }^{6}$ but consanguinity was present in only one of these 10 patients. Eight of our patients $(1,2,4$ to 8,10$)$ had rapidly progressive encephalopathy with fluctuations in consciousness disturbance, which was consistent with the typical clinical picture of type II citrullinaemia. On the other hand, the symptoms of patients 3 and 9 were different from the others. Patient 3 showed slowly progressive neuropsychic symptoms which clinically resembled the manifestations of major mood disorders or schizophrenia, and in an advanced stage she often had syncopelike attacks, involving loss of consciousness for 5 to 20 minutes. All of these psychic symptoms, including the syncope-like attacks, disappeared after liver transplantation, so they were attributed to the metabolic abnormalities in this disease. In patient 9 it is difficult to determine the onset of type II citrullinaemia because she had had intractable epilepsy since childhood, and convulsions sometimes appear as a symptom of encephalopathy in type II citrullinaemia. However, until the age of 17 she was not affected by severe encephalopathy, even though her history of epilepsy was longer than 10 years. Thus, the clinical manifestations of type II citrullinaemia probably started at this age.

Another notable finding is the presence of visceral organ lesions including chronic pancreatitis and severe fatty liver. The first was found in half of our patients and also preceded the development of encephalopathy in all five One important cause of chronic pancreatitis in the patients with this disease is obstruction of 
the main pancreatic duct, requiring pancreaticojejunostomy. Recently, it has been shown that the pancreatic secretory trypsin inhibitor (PSTI) gene is strongly expressed in the liver of patients with this disease, ${ }^{24}$ and the serum level of PSTI was constantly high in the patients with type II citrullinaemia ${ }^{25}$ including those we examined. Both findings suggest that the pathogenesis of this pancreatic disorder is linked to that of type II citrullinaemia. Severe fatty metamorphosis was also seen in all seven patients who underwent liver transplantation. Fatty liver develops in various pathological conditions: hyperlipidaemia, alcohol or drug intoxication, malnutrition, etc. Citrullinaemia itself might produce fatty metamorphosis, and the hypertriglyceridaemia seen in our four patients may have contributed to this fatty change. Moreover, nutritional factors, especially a low protein diet, also may play an important part.

\section{THERAPEUTIC APPROACHES INCLUDING LIVER}

TRANSPLANTATION

From 1980 to 2000,43 patients with type II citrullinaemia were reported in the Japanese literature. ${ }^{826}$ The male:female ratio was 34:9 and the age of onset ranged widely from 11 to 72 years, with a mean was 34.4 years. ${ }^{16}$ Most of these patients received conservative treatments, including a low protein diet, dietary arginine supplementation, administration of sodium citrate, sodium benzoate, lactulose, non-absorbed antimicrobial agents, and branched chain amino acid infusion. These treatments certainly produced temporary relief in the patients. However, the follow up data disclosed that 21 patients died within a few years of onset, and 14 of these 21 died between 3 days and 17 months later. The patients still alive might be affected by severe organic brain damage. Thus, the long term prognosis of patients with this disease treated with conservative therapy is obviously bad.

The optimal goal of treatment in metabolic encephalopathy is to correct the underlying abnormal metabolism in the patient before irreversible brain damage occurs. Urea cycle enzyme disorders are liver based metabolic disorders and liver transplantation is, therefore, an ideal treatment. Several patients with enzymatic disorders in the urea cycle underwent successful liver transplantation. ${ }^{27-30}$ For type II citrullinaemia, five patients were previously reported to have had liver transplants (three received from living donors in our country ${ }^{8} 1012$ and two from cadaveric donors in foreign countries $^{911}$ ) and all five patients showed good postoperative courses. In this article we have described the therapeutic effects of living related liver transplantation in seven patients with type II citrullinaemia, with long term follow up in two patients. In these seven patients the metabolic abnormalities including hypercitrullinaemia and hyperammonaemia were immediately corrected after transplantation, and all neurological symptoms soon disappeared except in patient 10: this patient had had residual symptoms due to irreversible brain damage that occurred before operation, but no additional symptoms have developed postoperatively. Six of them have been leading normal social lives without any specific medical support. Thus, liver transplantation has produced dramatic therapeutic effects in patients with this disease.

To investigate the postoperative changes in brain function in these patients serial examinations by EEG and SPECT were carried out in patients 3, 4, 9, and 10: the EEG was normalised in patients 3 and 10 shortly after transplantation, but the abnormal SPECT findings remained unchanged in all four, even though their clinical pictures were rapidly improving. They had possibly had irreversible brain injuries before transplantation, as supported by the fact that CT and MRI images of patients 3 and 10 showed slight but apparent cortical atrophy on admission. Finally, we emphasise that adult onset type II citrullinaemia is not rare in Japan and is a curable disorder.

1 Brusilow SW, Horwich AL. Urea cycle enzymes. In: Scriver $\mathrm{CR}$, Beaudet AL, Sly WS, et al, eds. The metabolic and molecular bases of inherited disease. 7 th ed. New York: McGraw-Hill Information Service, 1995:1187-232.

2 Saheki T, Kobayashi K, Inoue I. Hereditary disorders of the urea cycle in man: biochemical and molecular approaches. Rev Physiol Biochem Pharmacol 1987;108:21-68.

3 Kobayashi K, Jackson MJ, Tick DB, et al. Heterogeneity of mutations in argininosuccinate synthetase causing human citrullinemia. F Biol Chem 1990;265:11361-7.

4 Kobayashi K, Shaheen N, Terazono H, et al. Mutations in argininosuccinate synthetase mRNA of Japanese patients, argininosuccinate synthetase mRNA of Japanese patients, causing class $1103-12$.

5 Kobayashi K, Shaheen N, Kumashiro R, et al. A search for the primary abnormality in adult-onset type II citrullinemia. Am f Hum Genet 1993;53:1024-30

6 Kobayashi K, Sinasac DS, Iijima M, et al. The gene mutated in adult-onset type II citrullinemia encodes a putative mitochondrial carrier protein. Nat Genet 1999;22:159-63.

7 Yasuda T, Yamaguchi N, Kobayashi K, et al. Identification of two novel mutations in the SLC25A13 gene and detection of seven mutations in 102 patients with adult-onset type II citrullinemia. Hum Genet 2000;107:537-45.

8 Takenaka K, Yasuda I, Araki H, et al. Type II citrullinemia in an elderly patient treated with living related partial liver an elderly patient treated with living related

9 Todo S, Starzl TE, Tzakis A, et al. Orthotopic liver transplantation for urea cycle enzyme deficiency. Hepatology 1992;15:419-22.

10 Yazaki M, Ikeda S, Takei Y, et al. Complete neurological recovery of an adult patient with type II citrullinemia after living related partial liver transplantation. Transplantation 1996;62:1679-81.

11 Kawamoto S, Strong RW, Kerlin P, et al. Orthotopic liver transplantation for adult-onset type II citrullinemia. Clin Transplantation 1997;11:453-8.

12 Kasahara M, Ohwada S, Takeichi T, et al. Living-related liver transplantation for type II citrullinemia using a graft from heterozygote donor. Transplantation 2001;71:157-9.

13 Saheki T, Kobayashi K, Ichiki H, et al. Molecular basis of enzyme abnormalities in urea cycle disorders: with special reference to citrullinemia and argininosuccinaic aciduria. Enzyme 1987;38:227-32.

14 Makuuchi M, Kawasaki S, Noguchi T, et al. Donor hepatectomy for living related partial liver transplantation. Surgery 1993;113:395-402.

15 Kawasaki S, Makuuchi M, Matsunami H, et al. Living related liver transplantation in adults. Ann Surg 1998;227: 269-74.

16 Kobayashi K, Iijima M, Yasuda T, et al. Type II citrullinemia (citrin deficiency): a mysterious disease caused by a defect of calcium-binding mitochondrial carrier protein. In: Pochet R, Donato R, Haiech J, et al, eds. Calcium: the molecular basis of calcium action in biology and medicine. Netherlands: Kluwer, 2000:565-87

17 Shiraki H, Yamamoto T, Yamada K, et al. An autopsied case of the "pseudoulegyria type" of the hepatocerebral disease. Seishinshinkeishi 1962;64:305-18. (In Japanese.)

18 Oda M. Ein Beitrag zu den klinischen und histopathologischen Problemen uber die hepatozerebralen Erkrankungen, isbesondere uber den"Pseudoulegyrie Typ" Seishinshinkeishi 1964;65:892-931. (In Japanese.)

19 Kretschmer E. Das appallische syndrom. Zeitschrift für Gesampte Neurologie und Psychiatrie 1940;169:576-9.

20 Shiraki H, Oda M. Pseudoulegyric type of hepatocerebral disease. Naika 1971;28:491-8. (In Japanease.) 
21 Tsuji T, Morita T, Matsuyama Y, et al. Sibling cases of chronic recurrent hepatocebral disense with hypercitrulchronic recurrent hepatocerebral disease with hypercitrul-
linemia. Gastroenterologia faponica (Tokyo) 1976;11:328linernia

22 Saheki T, Ueda A, Hosoya M, et al. Qualitative and quantitative abnormalities of argininosuccinate synthetase in citrullinemia. Clin Chim Acta 1981;109:325-35.

23 Saheki T, Ueda A, Hosoya M, et al. Enzymatic analysis of citrullinemia (12 cases) in Japan. Adv Exp Med Biol 1982; 153:63-76.

24 Kobayashi T, Nakata $M$, Terazono $H$, et al. Pancreatic secretory trypsin inhibitor gene is highly expressed in the liver of adult-onset type II citrullinemia. FEBS Lett 1995;372:69-73.

25 Kobayashi K, Horiuchi M, Saheki T. Pancreatic secretory trypsin inhibitor as a diagnostic marker for adult-onset type II citrullinemia. Hepatology $1997 ; 25: 1160-5$.
26 Ishikawa F, Nakamuta $M$, Kato $M$, et al. Reversibility of serum $\mathrm{NH}_{3}$ level in a case of sudden onset and rapidly progressive case of type 2 citrullineimia. Intern Med 2000;39: 925-9.

27 Largilliere C, Houssin D, Gottrand F, et al. Liver transplantation for ornithine transcarbamylase deficiency in a girl. Paediatrics 1989;115:415-17.

28 Mowat AP. Orthotopic liver transplantation in liver-based metabolic disorders. Eur f Pediatr 1992;151(suppl 1): S32-8.

29 Jan D, Poggi F, Jouvet P, et al. Definitive cure of hyperammonemia by liver transplantation in urea cycle defects: report of three cases. Transplant Proc 1994;26:188.

30 Saudubray JM, Touati G, Delonlay P, et al. Liver transplantation in urea cycle disorders. Eur f Pediatr 1999;158(suppl 2):S55-9.

NEUROLOGICAL STAMP

\section{Robert Debre (1882-1978)}

Debre studied philosophy and, later, medicine. He subsequently became a professor of bacteriology and paediatrics.

In 1935 Debre (with Semelaigne) described a clinical syndrome resembling myotonia congenita but associated with cretinism. Debre syndrome is the enlargement of muscles caused by cretinism. Debre was honoured philatelically by France in 1981, which was the 100th year of his birth (Stanley Gibbons 2517, Scott B545).

L F HAAS

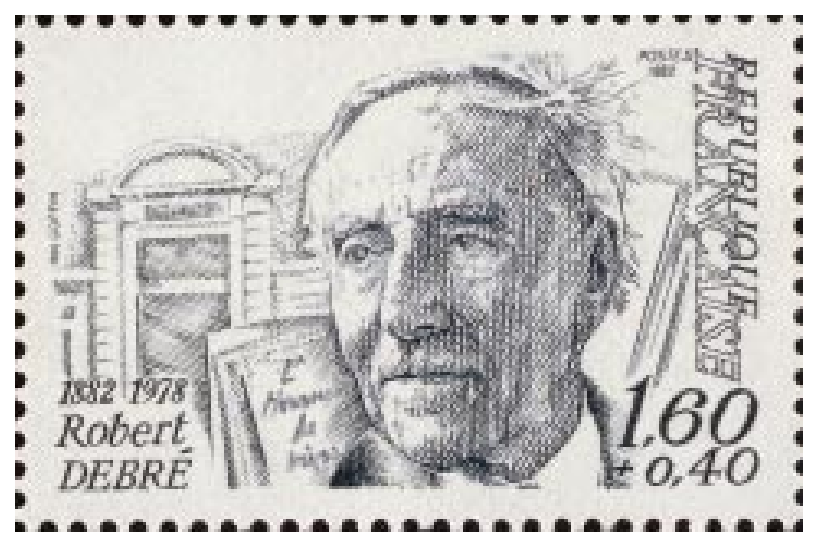

